\title{
EVA Bazlı Reçine Modifiyeli Bitümlü Karışımların Mekanik Özellikler Bakımından SBS Modifikasyonu ile Karşılaştırılması
}

\author{
Beyza FURTANA ${ }^{1}$, Erkut YALÇIN ${ }^{2 *}$, Baha Vural KÖK², Mehmet YILMAZ \\ 1 İnsaat Mühendisliği Bölümü, Mühendislik Fakültesi, Munzur Üniversitesi, Tunceli, Türkiye \\ 2 İnşaat Mühendisliği Bölümü, Mühendislik Fakültesi, Fırat Üniversitesi, Elazı̆̆, Türkiye \\ ${ }^{1}$ beyzafurtana@munzur.edu.tr, ${ }^{* 2}$ erkutyalcin@firat.edu.tr, ${ }^{2}$ bvural@ firat.edu.tr, , ${ }^{2}$ mehmetyilmaz@ firat.edu.tr,
}

Öz: Yol esnek üstyapısında kullanılan bitümlü kaplama tabakaları trafiğin ve çevrenin etkilerine direk maruz kalan ve dolayısıyla mekanik özellikler bakımından oldukça sağlam olması gereken en üst tabakadır. Bitümlü sıcak karışım tabakalarının artan trafik yükü ve sayısına uzun süre deforme olmadan direnç gösterebilmesi için, yaygın bir şekilde karışımın içinde kullanılan bağlayıcı bitümlü malzeme, Stiren-Butadien-Stiren (SBS) polimer katkı maddesiyle modifiye edilmektedir. SBS'e olan talebin fazla olması, gerektiği zamanda temin edilmesini zorlaştırmakta ve dolayısıyla alternatif katkı maddelerinin kullanımı gündeme getirmektedir. Bu çalıșmada Etilen-Vinyl-Acetate (EVA) bazlı reçinenin (EBR) bitümlü karıșımlarda kullanılmalarının mekanik özelliklere etkisi araştırılmış ve SBS modifikasyonu ile performansı karşılaştırılmıştır. Saf ve modifiye karışımlara Marshall stabilite ve akma, indirek çekme mukavemeti, indirek çekme rijitlik modülü, indirek çekme tekrarlı yükleme ve dinamik sünme deneyleri uygulanmıştır. Sonuçta EBR modifikasyonunun saf karışımlardan önemli derecede daha iyi performans özelliklerine sahip olduğu ve SBS modifikasyonuna yakın bir performans gösterdiği tespit edilmiştir.

Anahtar kelimeler: Bitümlü karışım, modifikasyon, EVA, SBS, mekanik özellikler.

\section{The Comparison of the EVA Based Resin Modified Bituminous Mixtures to SBS Modification in Terms of Mechanical Properties}

\begin{abstract}
The bituminous coating layers used in the flexible pavement are the top layer that is directly exposed to the effects of the traffic and the environment and therefore must be quite robust in terms of mechanical properties. The bituminous binder used in the mixture, is commonly modified with the Styrene-Butadiene-Styrene (SBS) polymer additive so that the bituminous hot mixtures can resist to the increased traffic load and number for a long time without deforming. The high demand for SBS makes it difficult to supply when necessary and therefore brings on the use of alternative additives. In this study, the effects of the use of Ethylene-Vinyl-Acetate (EVA) based resin (EBR) on the mechanical properties of bituminous mixtures were investigated and their performance was compared with SBS modification. Marshall stability and flow, indirect tensile strength, indirect tensile stiffness modulus, indirect tensile cycling loading and dynamic creep tests were applied to pure and modified mixtures. As a result, it was found that EBR modification had significantly better performance compared to pure mixtures and showed close performance to SBS modification.
\end{abstract}

Key words: Bituminous mixtures, modification, EVA, SBS, mechanical properties.

\section{Giriş}

Esnek üstyapılar; alttemel, temel ve kaplama tabakalarından oluşmaktadır. Taşıt lastiklerinin temas ettiği ve üstyapının en pahalı kısmı olan kaplama tabakası; sathi kaplamadan bitümlü sıcak karışıma (BSK) kadar değişik yöntemlerle inşa edilebilmektedir. Sathi kaplamalar uygun temel üzerine uygulanan bitüm ve daha sonra da agreganın serilip sıkıştırılması şeklinde yapılmaktadır. Bitümlü sıcak karışımlar ise hem dayanıklı hem de pahalı bir kaplama türüdür. BSK'lar sabit bir tesiste agrega ve bitümün 1sıtılması ve karıștırılması, daha sonra uygulama yerine taşınarak belirli bir sıcaklıkta sıkıştırılması şeklinde uygulanmaktadır. BSK'larda agrega, karışımın içsel sürtünme direncini ve stabilitesini; bitümlü bağlayıcı ise kohezyonu sağlamaktadır. Bitümlü bağlayıcı ayrıca agrega tanelerini birbirine bağlayarak trafik yükleri altında dağılmasını önlemekte, düzgün yüzeyler sağlayarak sürüş konforunu ve karışımın stabilitesini arttırmakta, boşlukları doldurarak geçirimsizliği sağlamaktadır.

Esnek üstyapı kaplamalarında, artan trafik yükü ve iklim koşullarına bağlı olarak meydana gelen tekerlek izi, soyulma, çatlama, ondülasyon gibi bozulmaları geciktirmek, bakım ve yenileme gereksinimini daha seyrek

\footnotetext{
${ }^{*}$ Sorumlu yazar: erkutyalcin @ firat.edu.tr. Yazarların ORCID Numarası: ${ }^{1} 0000-0003-4565-7324,{ }^{2}$ 0000-0002-6389-4211, ${ }^{2} 0000-0002-$

$7496-6006,{ }^{20000-0002-2761-2598 ~}$
} 
aralıklara düşürmek ve kaplama performansını arttırmak amacıyla bitümlü bağlayıcılara veya karışımlara çeşitli katkı maddeleri eklenerek özellikleri iyileştirilmiş modifiye bitümler veya karışımlar elde edilmektedir [1-3]. Modifikasyon işlemi yaş ve kuru proses olmak üzere iki türlü gerçekleşmektedir. Yaş proses katkı maddelerinin doğrudan bitüme, kuru proses ise katkı maddelerinin karışıma ilave edilmesiyle oluşturulmaktadır. Modifiye bitüm üretilmesinde elastomer ve plastomer polimerlerin yanı sıra polimer olmayan kimyasal katkı maddeleri ile göl asfaltları, kaya asfaltları ve Gilsonitler gibi doğal katkı maddeleri de kullanılmaktadır. Bu katkı maddeleri içerisinde en çok Stiren-Butadien-Stiren (SBS) blok kopolimerleri kullanılmaktadır. Bir polimer çeşidi olan SBS en sık kullanılan katkı malzemesidir [4]. Yapılan çeşitli çalışmalarda bitüm modifikasyonunda SBS kullanımının bitümlü sıcak karışımların kalıcı deformasyona [5,6], nem hasarına [7,8], yüksek sıcaklıklarda tekerlek izi oluşumu ve yorulmaya karşı dayanımını arttırdığı belirlenmiştir [9-13].

SBS'nin aşırı bir şekilde kullanılması, istenilen zamanında tedarik edilmesini sınırlamaktadır. Bu nedenle araştırmacılar SBS modifikasyonuyla elde dilen karışım kadar iyi bir performans sağlayan alternatif katkı maddelerine odaklanmışlardır. Bu çalışmada, Etilen-Vinyl-Acetate (EVA) bazlı reçinenin (EBR) bitümlü karışımlarda kullanılmalarının mekanik özelliklere etkisi araştırılmış ve SBS modifikasyonu ile performansı karşılaştırılmıştır. Her iki katkı da saf bitüme ağırlıkça \%3 oranında eklenmiş karışımlara Marshall stabilite ve akma, indirek çekme mukavemeti, indirek çekme rijitlik modülü, indirek çekme tekrarlı yükleme ve dinamik sünme deneyleri uygulanmıştır. Ayrıca EBR katkılı karışımlar ile SBS katkılı karışımların mekanik performansları incelenmiş ve karşılaştırılmıştır.

\section{Malzeme ve Metot}

Çalışmada saf bağlayıcı olarak TÜPRAŞ Batman rafinerisinden temin edilen B 50/70 sınıfı bitüm kullanılmıştır. Saf bağlayıcı iki farklı katkı ile modifiye edilmiştir. Çalışmada özgül ağırlığı 1,14, yumuşama noktas $190{ }^{\circ} \mathrm{C}$, viskozitesi $80000 \mathrm{mPa} . \mathrm{s}$ ve nem oran $\%$ 8-10 olan Etilen Vinil Asetat (EVA) bazlı reçine (EBR) diğeri ise özgül ağırlığı 0,94, uzama kompasına \%880, çekme direncine 4600 psi ve \% 31/69 styrene- kauçuk içeriğine sahip Stiren-Butadien-Stiren (SBS) blok kopolimer ihtiva eden KRATON D 1101 katkıları kullanılmıştır. SBS KRATON D 1101 konsantrasyonları daha öncede yapılan çalışmaların sonuçlarına göre bitüme ağırlıkça \%3\%9 arasında eklenmiştir [14]. Maliyet bakımından herhangi bir fark oluşmaması için her iki katkı da aynı oranda ve özellikle SBS'nin yol inşaatı uygulamalarında sıkça kullanılan oranı olan \%3 seçilmiştir. Daha önceden yapılan çalışmalara göre modifiye bağlayıcılar, katkı malzemesinin saf bağlayıcıya yavaş yavaş ilave edilerek, dört bıçaklı karıştırıcı ile 1000 devir/dakika hıza sahip karıştırıcıda $180^{\circ} \mathrm{C}$ sabit sıcaklıkta 1 saat süre ile karıştırılarak elde edilmiştir [15-17]. Şekil 1'de kullanılan katkı maddeleri ve modifiye bitüm hazırlama mikseri görülmektedir. Modifiye bitüm hazırlama sırasında meydana gelen yaşlanma etkisinin sonuçları etkilememesi için hiç katkı içermeyen saf bağlayıcı da aynı karıştırma işlemine tabi tutulmuştur. Tablo 1'de bağlayıcıların fiziksel özellikleri verilmiştir.

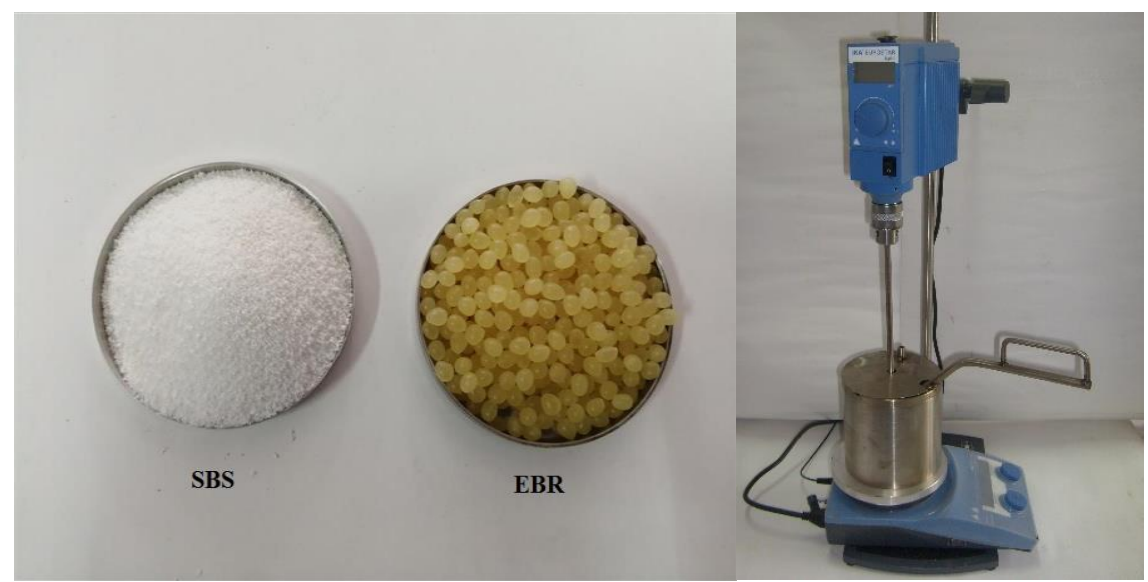

Şekil 1 Çalışmada kullanılan katkı maddeleri ve modifiye bitüm hazırlama mikseri. 
Tablo 1. Bağlayıcıların fiziksel özellikleri.

\begin{tabular}{|l|c|c|c|}
\hline Özellikler & B 50/70 saf & \%3SBS katk1l & \%3EBR katk1l1 \\
\hline $\begin{array}{l}\text { Yumuşama noktas1 }\left({ }^{\circ} \mathrm{C}\right) \\
\text { ASTM D36 }\end{array}$ & 53,3 & 61,7 & 58,7 \\
\hline $\begin{array}{l}\text { Penetrasyon }(0,1 \mathrm{~cm}) \\
\text { ASTM D5 }\end{array}$ & 64,2 & 49,0 & 56,7 \\
\hline Penetrasyon indeksi & 0,22 & 1,33 & 1,08 \\
\hline $\begin{array}{l}\text { Viskozite } 135^{\circ} \mathrm{C} / 165^{\circ} \mathrm{C} \\
\text { ASTM D4402 }\end{array}$ & $725 / 225$ & $1875 / 475$ & $1100 / 287$ \\
\hline
\end{tabular}

Saf, \%3 EBR ve \%3 SBS modifiyeli bağlayıcılar ile bitümlü karışım numuneleri hazırlanmıştır. Karışım numuneleri Marshall yöntemine göre numunelerin her iki yüzüne 75 darbe uygulanarak hazırlanmıştır. Karışımlarda agrega olarak özellikleri ve gradasyonu Tablo 2'de verilen kireçtaşı kullanılmıştır. Kireçtaşı Elazı ̆ Karayazı bölgesinden temin edilmiştir. Optimum bitüm içeriği saf bitüm ile hazırlanan karışım numuneleri için tespit edilmiştir. Modifiye karışımlar da aynı bitüm içeriğinde hazırlanmıştır.

Tablo 2. Agrega özellikleri ve gradasyonu.

\begin{tabular}{|c|c|c|c|c|c|c|c|c|c|c|c|c|}
\hline \multicolumn{5}{|c|}{ 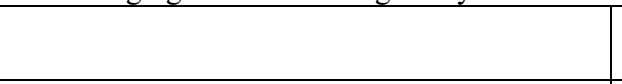 } & \multicolumn{2}{|c|}{ Kaba } & \multicolumn{2}{|c|}{ İnce } & \multicolumn{2}{|c|}{ Filler } & $\begin{array}{l}\text { Şartname } \\
\text { limiti }\end{array}$ & $\begin{array}{c}\text { Deney } \\
\text { Standard1 }\end{array}$ \\
\hline \multicolumn{5}{|c|}{ Los Angeles aşınma (\%) ASTM D131 } & \multicolumn{2}{|c|}{25} & \multicolumn{2}{|c|}{-} & \multicolumn{2}{|c|}{-} & Maks. 35 & $\begin{array}{l}\text { ASTM } \\
\text { C-131 }\end{array}$ \\
\hline \multicolumn{5}{|c|}{ Hava tesirlerine direnç $\left(\mathrm{MgSO}_{4}\right)$ ASTM C88 } & \multicolumn{2}{|c|}{12} & \multicolumn{2}{|c|}{-} & \multicolumn{2}{|c|}{-} & Maks. 10 & $\begin{array}{c}\text { ASTM } \\
\text { C- } 88\end{array}$ \\
\hline \multicolumn{5}{|c|}{ Yass1 ve uzun dane (\%) BS 812} & \multicolumn{2}{|c|}{20} & \multicolumn{2}{|c|}{-} & \multicolumn{2}{|c|}{ - } & Maks. 10 & $\begin{array}{l}\text { ASTM } \\
\text { D-4791 }\end{array}$ \\
\hline \multicolumn{5}{|c|}{ Su absorbsiyonu (\%) ASTM C127 } & \multicolumn{2}{|c|}{0,8} & \multicolumn{2}{|c|}{-} & \multicolumn{2}{|c|}{-} & - & - \\
\hline \multicolumn{5}{|c|}{ Hacim özgül ağırlık ASTM C127, C128 } & \multicolumn{2}{|c|}{2,521} & \multicolumn{2}{|c|}{2,558} & \multirow{2}{*}{\multicolumn{2}{|c|}{2,596}} & - & - \\
\hline \multicolumn{5}{|c|}{ Zahiri özgül ağırlık ASTM D854 } & \multicolumn{2}{|c|}{ - } & \multicolumn{2}{|c|}{-} & & & - & - \\
\hline Elek çap1 (mm) & 19 & 12,5 & 9,5 & 4,75 & 2,36 & 1,18 & 0,6 & 0,3 & \multicolumn{2}{|c|}{$0,15 \quad 0,075$} & - & - \\
\hline$\%$ Geçen & 100 & 95 & 88 & 65 & 35 & 23 & 14 & 10 & 8 & 6 & - & - \\
\hline
\end{tabular}

Tablo 3'te \%5,5 bitüm içeriğinde hazırlanan saf ve modifiye karışımların, hava boşluğu oranı (Va), asfaltla dolu boşluk oranı (VFA), agregalar arasındaki boşluk oranı (VMA), hacim özgül ağırlıkları (Gmb), karıştırmasıkıştırma sıcaklıkları verilmiştir. Karışımların karıştırma-sıkıştırma sıcaklıkları bağlayıcıya uygulanan dönel viskozimetre yöntemine göre sırasıyla $170 \pm 20$ ve $280 \pm 30 \mathrm{cP}$ viskozite değerlerine karşı gelen sıcaklıklar olarak belirlenmiştir [18]. Karışım numunelerinin hacimsel özellikler bakımından şartname kriterlerini (KTŞ) sağladığı tespit edilmiştir.

Tablo 3. Karışım numunelerinin hacimsel özellikleri.

\begin{tabular}{|l|c|c|c|c|c|c|c|}
\hline Karışımlar & $\begin{array}{c}\text { Bitüm } \\
(\%)\end{array}$ & $\begin{array}{c}\text { Karıştırma } \\
\text { sicaklığ } 1\left({ }^{\circ} \mathrm{C}\right)\end{array}$ & $\begin{array}{c}\text { Sikıştırma } \\
\text { sicaklı̆̆ }\left({ }^{\circ} \mathrm{C}\right)\end{array}$ & Va (\%) & VFA (\%) & VMA (\%) & Gmb \\
\hline Saf & 5,5 & $170-177$ & $153-158$ & 3,78 & 74,3 & 14,7 & 2,292 \\
\hline$\% 3$ EBR & 5,5 & $175-181$ & $162-168$ & 3,69 & 74,7 & 14,6 & 2,295 \\
\hline$\% 3$ SBS & 5,5 & $189-195$ & $181-176$ & 3,92 & 73,5 & 14,8 & 2,289 \\
\hline
\end{tabular}

\section{Deneysel Sonuçlar}

\subsection{Marshall stabilite ve akma deneyi}

Bitümlü karışımların bir performans göstergesi olan Marshall stabilite ve akma deneyi ASTM D 6927 standardına uygun olarak yapılmıştır. Şekil 2 de Marshall stabilite ve akma deney cihazı ve numuneleri görülmektedir. Çalışmada saf ve modifiye karışım numuneleri iki gruba ayrılmıştır. Birinci grup numuneler $60^{\circ} \mathrm{C}$ 'lik su banyosunda 40 dakika bekletildikten sonra deneye tabi tutulmuş ve stabiliteleri $\mathrm{MS}_{\text {koşulsuz }}$ değerler olarak tespit edilmiştir. İkinci grup numuneler 24 saat $60^{\circ} \mathrm{C}$ 'lik su banyosunda bekletildikten sonra deneye tabi tutulmuş ve stabiliteleri $\mathrm{MS}_{\text {koşullu }}$ değerler olarak tespit edilmiştir. Rijitliğin bir göstergesi olan stabilitenin akmaya oranı (MQ) koşullu ve koşulsuz numuneler için tespit edilmiştir. Nem hasarına karşı direncin bir göstergesi olan 
kalıcı Marshall stabilitesi (RMS) koşullu numunelerin, koşulsuz numunelerin stabilitelerine oranı olarak tespit edilmiştir. RMS değeri Denklem 1 ile hesaplanmaktadır.

$R M S=\frac{M S_{\text {koșullu }}}{M S_{\text {koşulsuz }}} \times 100$

Tablo 4'te deneyden elde edilen sonuçlar verilmiştir. Koşulsuz durumda SBS ve EBR modifikasyonu saf karışımdan sırasıyla \%8 ve \%6 daha yüksek stabilite değerleri vermiştir. Koşullu durumda ise bu oranlar her iki modifikasyon için de \%14 olmaktadır. Koşullandırma sonrası saf karışım stabilitesinin \%14'ünü kaybederken SBS ve EBR modifikasyonunda bu kayıp sırası ile \%8,5 ve \% 7,5 olmaktadır. MQ değerleri bakımından modifiye karışımlar saf karışımdan koşulsuz durumda yaklaşık \%25, koşullu durumda ise \%10 daha rijit davranış göstermiştir. Bütün karışımlar \%80 oranından daha yüksek RMS değeri vererek nem hasarı bakımından olumsuz bir durumun oluşmadığı görülmektedir. Ancak modifiye karışımlar saf karışımdan bir miktar daha yüksek RMS değerine sahip olarak saf karışımdan daha iyi nem hasarlarına direnç göstereceğine işaret etmektedir. Stabilite bakımından SBS modifikasyonu EBR modifikasyonundan bir miktar daha yüksek değerler verse de RMS bakımından bu durum bir miktar EBR modifikasyonu açısından iyileşmektedir.

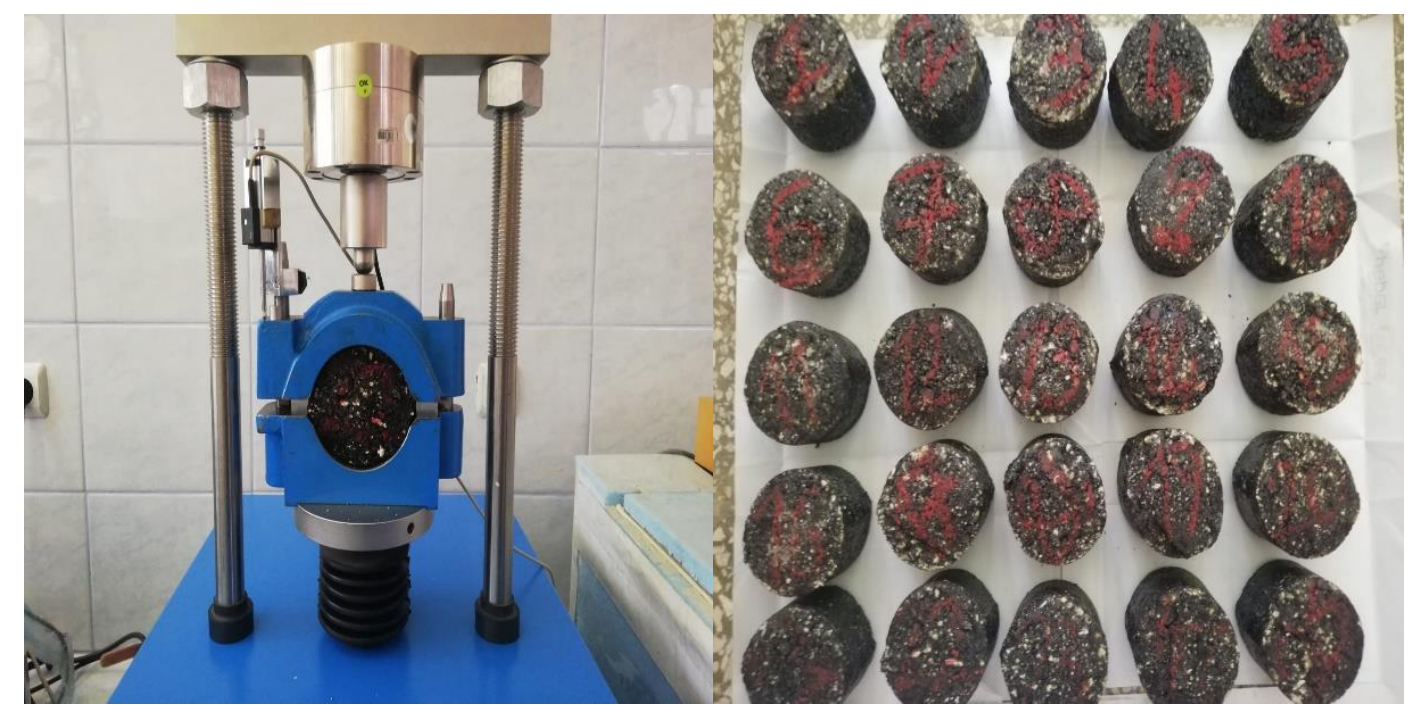

Şekil 2 Marshall test cihazı ve Marshall numuneleri

Tablo 4. Marshall stabilite ve akma deney sonuçları.

\begin{tabular}{|c|c|c|c|c|c|c|c|}
\hline \multirow{2}{*}{ Karışımlar } & \multicolumn{3}{|c|}{ Koşulsuz } & \multicolumn{4}{c|}{ Koşullu } \\
\cline { 2 - 8 } & Stabilite $(\mathrm{kN})$ & Akma & $\mathrm{MQ}_{1}$ & Stabilite $(\mathrm{kN})$ & Akma & $\mathrm{MQ}_{2}$ & $\mathrm{RMS}_{(\%)}$ \\
\hline Saf & 14,62 & 3,61 & 4,04 & 12,6 & 4,38 & 2,87 & 86,18 \\
\hline$\% 3$ SBS & 15,78 & 3,14 & 5,02 & 14,43 & 4,49 & 3,21 & 91,44 \\
\hline$\% 3 E B R$ & 15,54 & 3,11 & 4,99 & 14,4 & 4,63 & 3,11 & 92,66 \\
\hline
\end{tabular}

\section{2 İndirek çekme rijitlik modülü (ITSM) deneyi}

Bitümlü tabakaların yük dağıtma kabiliyetinin bir ölçüsü olan rijitlik modülü, bitümlü sıcak karışımların en önemli performans karakteristiklerinden biridir [19]. Bu deney BS DD 213 standardı ile tanımlanmış hasarsız bir deney olup rijitlik modülü (Sm, MPa) Denklem 2 ile hesaplanmaktadır.

$\mathrm{Sm}=\mathrm{F}(\mathrm{R}+0,27) / \mathrm{LH}$

Burada F, maksimum dikey yük $(\mathrm{N})$; H, 5 yük tekrarı sonucunda oluşan ortalama yatay deformasyon $(\mu \mathrm{m})$; $\mathrm{L}$, ortalama numune kalınlığı (mm); R ise poisson oranınıdır $(0,35)$. Deney, $25^{\circ} \mathrm{C}$ sıcaklıkta deformasyon kontrollü olarak yapılmıştır. Maksimum deformasyon $6 \mu \mathrm{m}$, yükleme periyodu $3 \mathrm{sn}$, yük artış süresi 0,124 s olarak alınmıştır. Deneye başlamadan önce numuneler 2 saat deney sıcaklığında bekletilmiştir 
Deney $25^{\circ} \mathrm{C}$ ve $35^{\circ} \mathrm{C}$ olmak üzere iki farklı sıcaklıkta yapılmıştır. ITSM değerlerinin karışım tipine göre değişimi Şekil 3'te verilmiştir. SBS ve EBR modifikasyonu saf karışımdan $25^{\circ} \mathrm{C}$ 'de sırasıyla $\% 40$ ve $\% 38,35^{\circ} \mathrm{C}$ sicaklıkta ise $\% 34$ ve $\% 25$ daha yüksek ITSM değerleri vermiştir. SBS modifikasyonu EBR modifikasyonundan $25^{\circ} \mathrm{C}$ 'de $\% 1,735^{\circ} \mathrm{C}^{\prime}$ de ise $\% 7$ daha yüksek ITSM değeri vermektedir. Bu durum SBS modfikasyonunun EBR modifikasyonuna göre sıcaklığa karşı bir miktar daha az duyarlı olduğuna işaret etmektedir. Sicaklığın $25^{\circ} \mathrm{C}$ 'den $35^{\circ} \mathrm{C}$ 'ye $10^{\circ} \mathrm{C}$ artması durumunda karışımların rijitlikleri yarısından fazla azalmaktadır. Sıcaklığın rijitlik modülü üzerinde önemli bir etkiye sahip olduğu, dolayısıyla yüksek rijitlik modülünün, yüksek kaplama sıcaklıklarında kaplamanın bütünlüğünü koruyabilmesi için gerekli olduğu görülmektedir. SBS ve EBR modifikasyonu ITSM değerleri bakımından birbirine benzer ancak saf karışımdan önemli derecede daha iyi bir performans göstermiştir. Şekil 4'te yükleme sırasında numunelerde oluşan deformasyonun $400 \mathrm{~ms}$ içerisindeki değiş̧imi verilmiştir. Şekilde görüldügüü üzere yük etkisi süresince yanal deformasyonlar hedef deformasyon olan 6 mikron değerine ulaşmakta ve yük kalktıktan sonra geri dönmektedir. En hızlı deformasyon dönüşünün SBS modifikasyonunda sonra EBR ve saf karışımda olduğu görülmektedir. 400. ms saniyede geri dönem deformasyonlar bakımından SBS ve EBR modifiyeli karışımlar benzer performans göstermektedir.

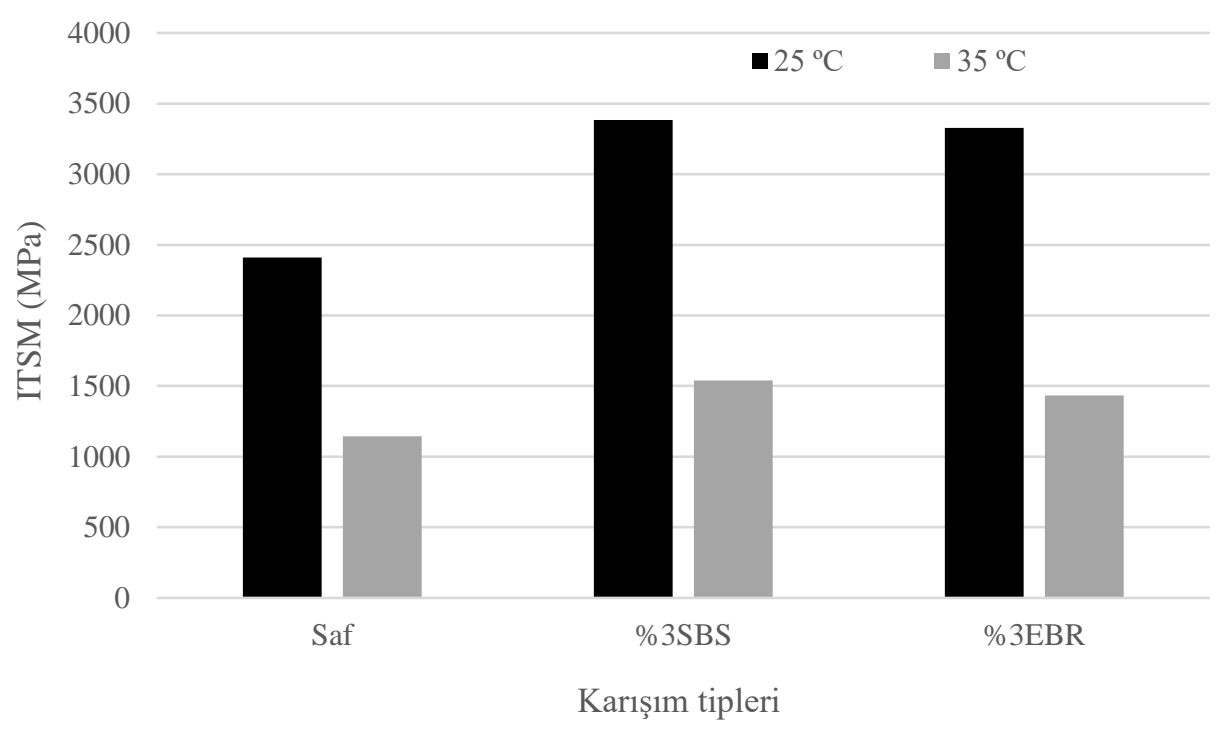

Şekil 3 ITSM değerlerinin karışım tipine göre değişimi.

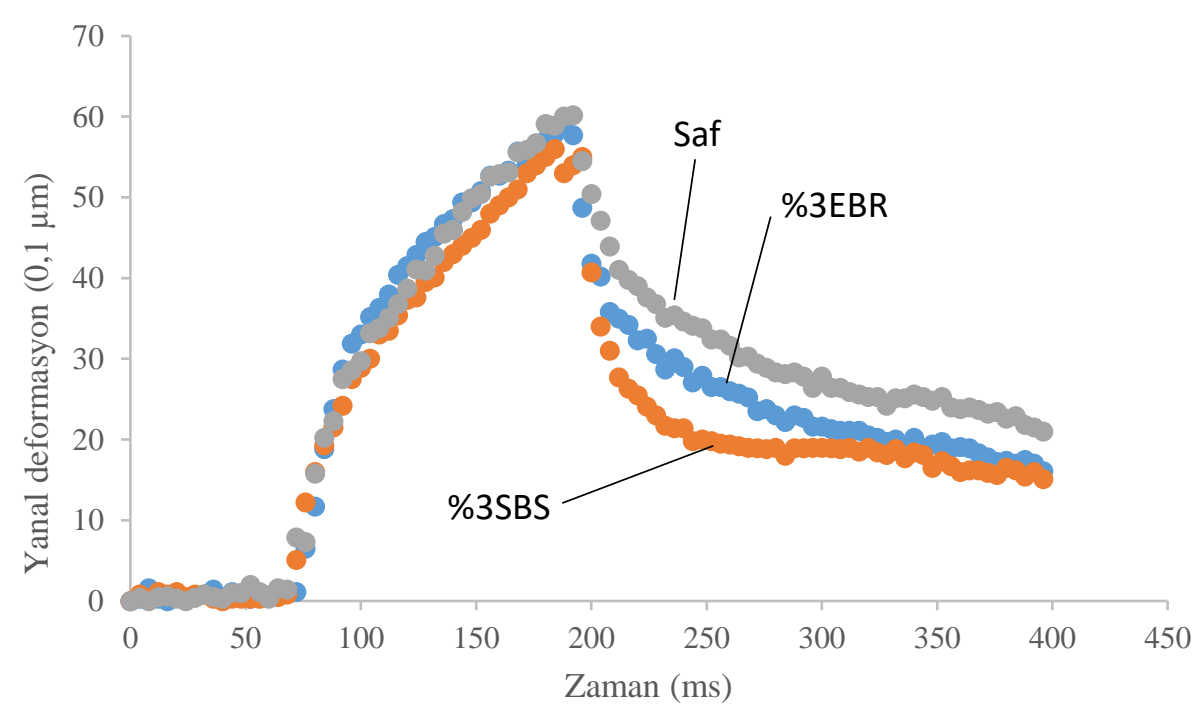

Şekil 4. ITSM deneyinde deformasyon zaman ilişkisi. 


\section{3 İndirek çekme mukavemeti (ITS) deneyi}

Deney sonuçları Marshall test cihazı kullanılarak tespit edilmiştir. Silindirik numunelerin basınç yüklemesine tabi tutulduğu, numunenin düşey çapsal düzlemi doğrultusunda üniform bir gerilme dağılımı oluşturan deneyde, kırılmaya neden olan yük tespit edilip, Denklem 3 bağıntısı ile ITS (kPa) değerleri hesaplanmıştır.

$\mathrm{ITS}=2 \mathrm{P}_{\text {maks }} / \pi \mathrm{td}$

Burada P, kırılmaya neden olan maksimum yük $(\mathrm{kN})$; t, ortalama numune yüksekliği $(\mathrm{m})$; d, numune çapıdır (m). Şeki 5'te karışımların ITS değerleri verilmiştir. SBS ve EBR modifiyeli karışımların ITS değerleri birbirine yakın çıkarken modifiyeli karışımlar saf karışımdan \%15 daha yüksek ITS değeri vermiştir. Modifiyeli karışımların MQ değerleri ve ITSM değerlerine göre rijitliklerinde meydana gelen artışın, $25^{\circ} \mathrm{C}^{\prime}$ de yapılan ITS deneyinde de çekme gerilmelerine karşı direncin artmasını sağladığı görülmektedir.

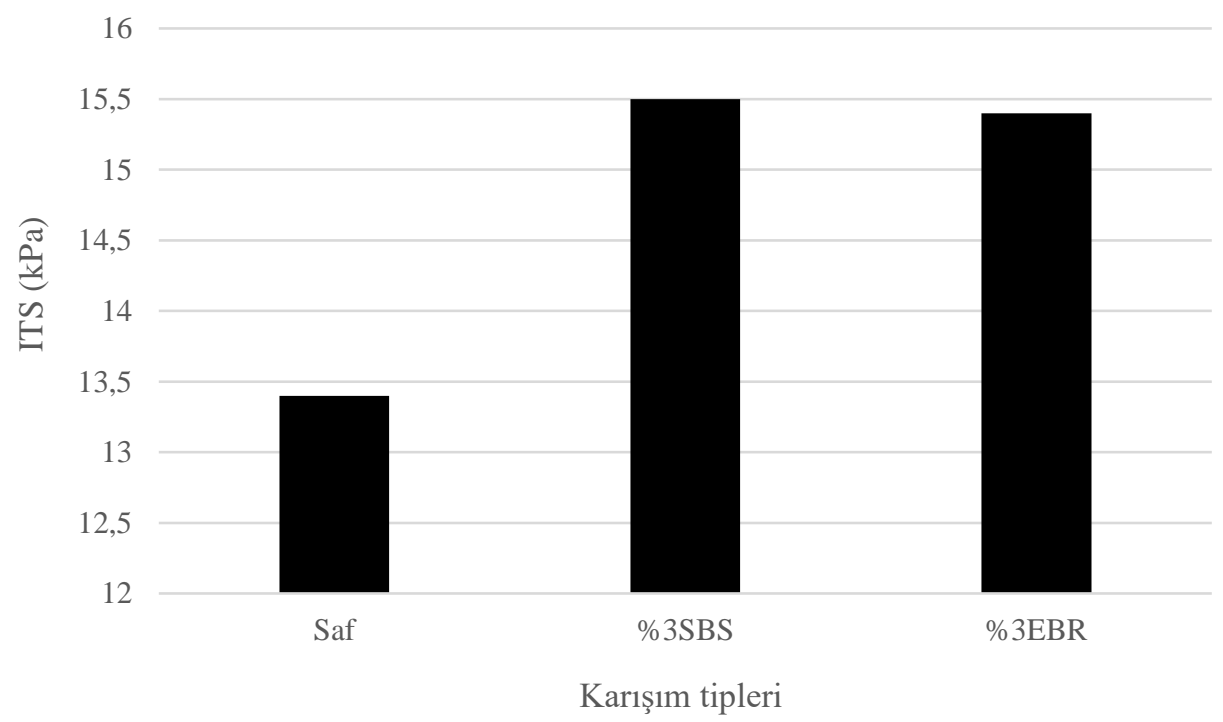

Şekil 5 Karışımların ITS değerleri.

\section{4 İndirek çekme tekrarlı yükleme deneyi}

Yol kaplamaları her taşıt tekerleği geçişinde kısa süreli bir yüke maruz kalırlar. Bu, malzemenin rijitliğinde azalmayla sonuçlanan çok küçük hasarlara neden olur. Bu hasarların birikmesi ile uzun sürede malzeme bozulmaktadır. Yorulma dayanımı, asfalt kaplamanın tekrarlı trafik yüklerine, dolayısıyla tekrarlı eğilme yüklemesine kırılmadan karşı koyabilme yeteneğidir. Deney, 25 ve $35^{\circ} \mathrm{C}$ sıcaklıklarda $270 \mathrm{kPa}$ sabit yük altında yapılmıştır. Deneye başlamadan önce numuneler 2 saat deney sıcaklığında bekletilmiştir. Bu süre sonunda numune, yükleme başlıkları arasına yerleştirilmiş, düşey deformasyonu okuyacak LVDT'ler ayarlanmış, numune yüksekliği, çapı, gerilme seviyesi değerleri ve yükleme periyodu bilgisayara girilmiş ve deneye başlanmıştır. Yükleme periyodu 1,5 sn olarak alınmış bu sürenin 1,4 sn'si dinlenme periyodu (rest period), 0,1 sn'si ise yük etki süresi olarak ayarlanmıştır. Deney, numuneler tam olarak kırılıncaya kadar devam etmiştir. Şekil 6 ve 7'de numunelerin deformasyon ve yük tekrarı ilişkisi verilmiştir. 


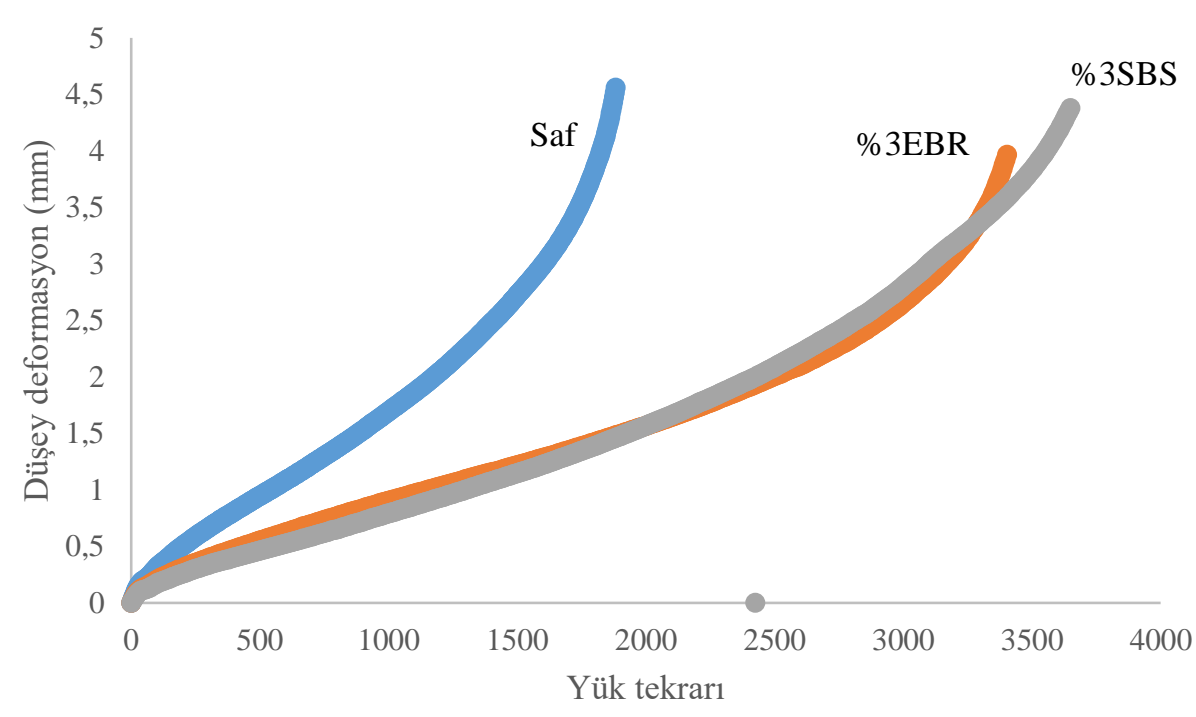

Şekil $625^{\circ} \mathrm{C}$ 'de yük tekrarı düşey deformasyon ilişkisi.

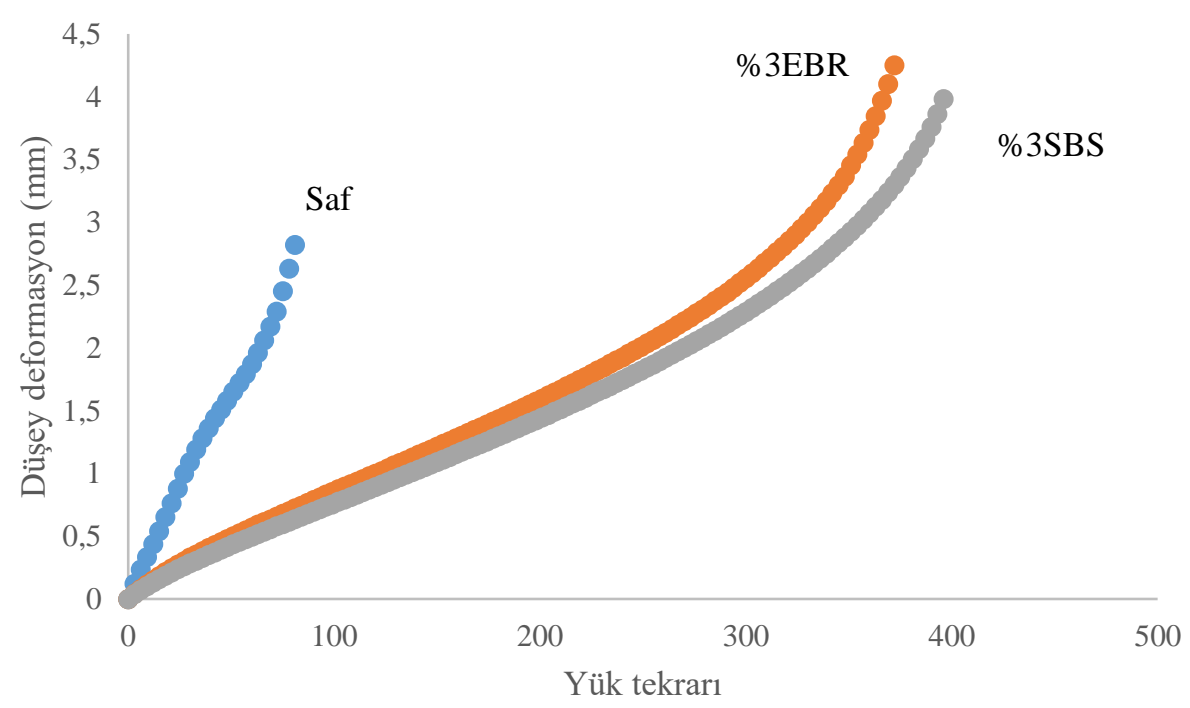

Şekil $735^{\circ} \mathrm{C}$ 'de yük tekrarı düşey deformasyon ilişkisi.

Numunelerin yük tekrar sayıları sıcaklığın artması ile önemli derecede azalmaktadır. Saf karışım $25^{\circ} \mathrm{C}$ 'de ortalama 2419 yük tekrarına direnç gösterebilirken $35^{\circ} \mathrm{C}$ 'de sadece 80 yük tekrarı alabilmiştir. $25^{\circ} \mathrm{C}$ 'de 3920 yük tekrarı alan SBS modifiyeli karışım $35^{\circ} \mathrm{C}$ 'de 394 yük tekrarı, EBR modifiyeli karışım ise sırasıyla 3400 ve 370 yük tekrarı almıştır. Saf karışımın yük tekrar sayısı sıcaklık artışı ile yaklaşık 30 kat azalırken modifiyeli karışımlarda bu oran yaklaşık 10 kat olmaktadır. SBS ve EBR modifikasyonu saf karışıma göre önemli derecede sıcaklık artışına direnç gösterebilmektedir. EBR modifiyeli karışımların yük tekrarı - deformasyon ilişkisi SBS modifiyeli karışımlara benzemekle birlikte SBS modifikasyonu EBR modifikasyonundan $25^{\circ} \mathrm{C}$ ' de $\% 15,35^{\circ} \mathrm{C}$ 'de ise $\% 6$ daha fazla yük tekrarına dayanabilmektedir. SBS ve EBR modifiyeli karışımlar saf karışımdan $25^{\circ} \mathrm{C}$ 'de sırasıyla 1,6 ve 1,4 kat $35^{\circ} \mathrm{C}^{\prime}$ de ise 4,9 ve 4,6 kat daha fazla yük tekrarına direnç gösterebilmektedir.

\subsection{Dinamik sünme deneyi}

Dinamik sünme deneyi bitümlü karışımların kalıcı deformasyonlara karşı direncinin belirlenmesinde kullanılan önemli bir deneydir ve tekerlek izi direnci ile yüksek bir korelasyona sahiptir [20]. Deneyde yük tekrarı 
ile birlikte oluşan şekil değiştirmeler, başta numunedeki hava boşluğunun sıkışması dolayısıyla hızlı bir şekilde artmakta daha sonra konsolide olan numunede lineer olarak devam etmekte ve numune bütünlüğünü yitirmeye başladıktan sonra hızlı bir şekilde artış göstermektedir [21]. Sünme rijitliği aşağıdaki denklemden tespit edilmektedir [22].

$E_{c}=\frac{\sigma}{\varepsilon_{c}}$

Burada $\mathrm{E}_{\mathrm{c}}$, sünme rijitliği $(\mathrm{MPa}), \sigma$, uygulanan dinamik gerilme $(\mathrm{MPa}), \varepsilon_{\mathrm{c}},(\sigma)$, toplam kalıcı şekil değiştirmedir. Deney $50^{\circ} \mathrm{C}$ sıcaklıkta ve $0,5 \mathrm{MPa}$ gerilme altında yapılmıştır. Numuneler deneye başlamadan önce 3 saat deney sıcaklığında bekletilmiştir. Deneyde $500 \mathrm{~ms}$ yük etki süresi olan $1000 \mathrm{~ms}$ 'lik yükleme periyodundaki kare dalga yükleme uygulanmıştır. Numuneler deneye başlamadan önce 10 dakika $0,1 \mathrm{MPa}$ statik gerilme altında koşullandırma yüklemesine maruz bırakılmıştır. Yükleme 7000 yük tekrarına kadar yapılmıştır. Ancak saf karışımlar yaklaşık 4000 yük tekrarında kırılmıştır.

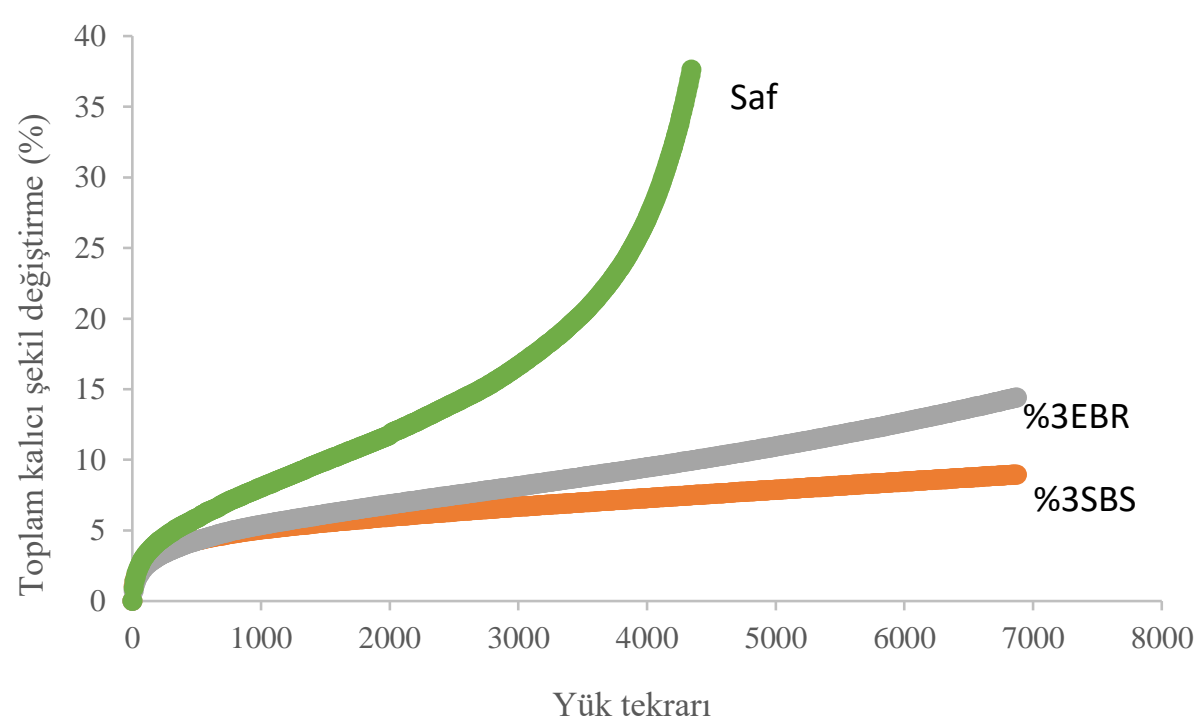

Şekil 8 Yük tekrarı şekil değiştirme ilişkisi.

Şekil 8'de görüldüğü üzere saf karışım katkılı karışımlardan önemli derecede fazla şekil değiştirmeye maruz kalmaktadır. Saf karışımda 3000 yük tekrarından sonra şekil değiştirmede meydana gelen artış numunenin bütünlüğünü yitirdiğini ve yük tekrarına direnç gösteremediğine işaret etmektedir. Saf karışım 4300 yük tekrarında tamamen parçalanmıştır. Katkılı karışımların şekil değiştirmesi ise 7000 yük tekrarında halen lineer bir değişim göstermektedir. EBR modifiyeli karışımlar SBS modifiyeli karışımlara benzer bir şekil değiştirme karakteristiği göstermektedir. Ancak karışımların şekil değiştirmeleri arasındaki fark yük tekrarının artması ile artmaktadır. SBS modifiyeli karışımlar yük tekrarına daha fazla direnç gösterebilmektedir. 3000 yük tekrarında saf karışım \%16, EBR modifiyeli karışım \%8 ve SBS modifiyeli karışım \%7 şekil değiştirmeye maruz kalmaktadır. Şekil 9'da karışımların, 4000 yük tekrarı sonundaki sünme rijitliği değerleri verilmiştir. SBS ve EBR modifiyeli karışım saf karışımdan sırasıyla 3 ve 2 kat daha fazla sünme rijitliği değerleri vermektedir. SBS modifikasyonu ise EBR modifikasyonundan \%60 daha yüksek sünme rijitliğine sahiptir. Ağır trafik ve yüksek hava sıcaklığının temsil edildiği şartlarda yapılan bu deneyde saf karışım ile katkılı karışımlar arasındaki performans farkı açık bir şekilde açığa çıkmıştır. Deney şartlarının zorlaşması katkıların etkinliğini değerlendirmede de etkili olmaktadır. 


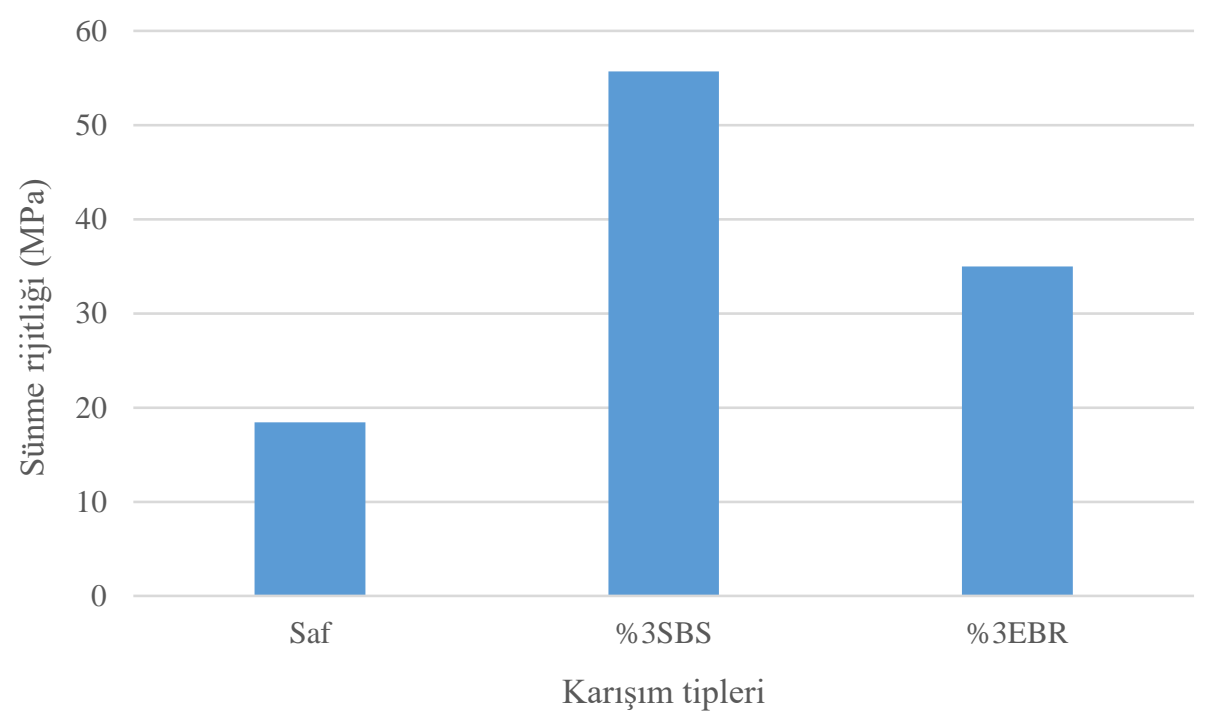

Şekil 9 Karışımların sünme rijitlikleri.

\section{Sonuçlar}

$\mathrm{Bu}$ çalışmada bitüm modifikasyonunda yaygın şekilde kullanılan SBS katkısına alternatif olabilecek EVA bazlı reçine katkısının, bitümlü karışımların mekanik özelliklerine olan etkisi araştırılmış ve SBS modifikasyonu ile karşılaştırılmıştır. Çalışmada kullanılan her iki katkı maddesi de bitüm ağırlığınca \%3 oranında kullanılmış ve bu modifiye bitümlerle hazırlanan Marshall numunelerine statik ve dinamik yükleme testleri uygulanmıştır. Marshall stabilite ve akma deneyine göre, katkılı karışımlar stabilite açısından benzer sonuçlar verirken saf karışımlardan koşulsuz durumda yaklaşık \% 7 , koşullu durumda ise $\% 14$ daha yüksek stabilite değeri vermektedir. Karışım numunelerinde nem hasarı bakımından olumsuz bir durumun oluşmadığı, ancak modifiye karışımların saf karışımdan bir miktar daha yüksek RMS değerine sahip olarak nem hasarlarına daha iyi direnç göstereceği tespit edilmiştir.

İki farklı sıcaklıkta yapılan ITSM deneyine göre saf ve modifiyeli karışımlarda sıcaklığın $10^{\circ} \mathrm{C}$ artması durumunda karışımların rijitlikleri yarısından fazla azalmaktadır. Katkılı bağlayıcıların rijitlikleri $25^{\circ} \mathrm{C}$ 'de saf bağlayıcıya göre yaklaşık \%40 oranında artmaktadır. SBS modifikasyonunun EBR modifikasyonuna göre sıcaklığa karşı bir miktar daha az duyarlı olduğu tespit edilmiştir.

ITS deneyine göre katkılı karışımların indirek çekme mukavemeti değerleri birbirine yakın çıkarken saf karışımdan \%15 daha yüksek olmaktadır.

İki farklı sıcaklıkta yapılan indirek çekme tekrarlı yükleme deneyine göre, saf karışımın yük tekrar sayısı sıcaklık artışı ile yaklaşık 30 kat azalırken modifiyeli karışımlarda bu oran yaklaşık 10 kat olmaktadır. EBR modifiyeli karışımların yük tekrarı - deformasyon ilişkisi SBS modifiyeli karışımlara benzemekle birlikte SBS modifikasyonu EBR modifikasyonundan $25^{\circ} \mathrm{C}$ 'de $\% 15,35^{\circ} \mathrm{C}^{\prime} \mathrm{de}$ ise $\% 6$ daha fazla yük tekrarına dayanabilmektedir.

Dinamik sünme deneyine göre saf karışım 4300 yük tekrarında tamamen parçalanmış, katkılı karışımlar ise 7000 yük tekrarında plastik deformasyon durumuna geçmemiştir. EBR modifiyeli karışımlar SBS modifiyeli karışımlara benzer bir şekil değiştirme karakteristiği göstermiştir.

Sonuç olarak ele alınan deney yöntemleri arasında indirek çekme tekrarlı yükleme deneyinin katkıların etkinliğini en fazla ön plana çıkaran deney olduğu, EVA bazlı reçinenin SBS modifikasyonuna yakın sonuçlar verdiği ve dolayısıyla SBS temininin sınırlı olduğu durumlarda, fiyatlarının da benzer olduğu dikkate alındığında alternatif bir katkı olarak kullanılabileceği tespit edilmiştir.

\section{Kaynaklar}

[1] Lav AH, Lav MA. Shell bitüm el kitabı. İsfalt Bilimsel Yayınları, 3, 334s, İstanbul, 2004

[2] Francken L. Bituminous binders and mixes. Rilem Reports, E\&FN Spon, 352, London, 1998.

[3] Nicholls C. Asphalt surfacings. E \& FN Spon, p. 68-79, 1998. 
[4] Şengöz B. Işıkyakar G. Evaluation of the properties and microstructure of SBS and EVA polymer modified bitumen. Construction and Building Materials 2008; 22(9), 1897-905.

[5] Kumar P. Chandra S, Bose S. Strength characteristics of polymer modified mixes. International Journal of Pavement Engineering 2006; 7(1): 63-71.

[6] Tayfur S, Özen H, Aksoy A. Investigation of Rutting Performance of Asphalt Mixtures Containing Polymer Modifiers. Construction and Building Materials 2007; 21(2), 328-337.

[7] Kök BV, Y1lmaz M. The effects of using lime and styrene-butadiene-styrene on moisture sensitivity resistance of hot mix asphalt. Construction and Building Materials 2009; 23, 1999-2006.

[8] Görkem Ç. Şengöz B. Predicting stripping and moisture induced damage of asphalt concrete prepared with polymer modified bitumen and hydrated lime. Construction and Building Materials 2009; 23, 2227-2236.

[9] Cortizo MS, Larsen DO, Bianchetto H, Alessandrini. J.L. Effect of the thermal degradation of SBS copolymers during the ageing of modified asphalts. Polymer Degradation and Stability 2004; 86, 275-282.

[10] Vlachovicova Z, Wkumbura C, Stastana J, Zanzotto L. Creep characteristics of asphalt modified by radial styrenebutadiene-styrene copolymer. Construction and Building Materials 2007; 21, 567-577411.

[11] Isacsson U, Zeng HY. Relationships between bitumen chemistry and low temperature behavior of asphalt. Construction and Building Materials 1997; 11, 83-91.

[12] Shuler S, Douglas I. Improving Durability Of Open-Graded Friction Courses. Transportation Research Record 1990; $1259,35-41$.

[13] Won MC, Ho MK. Effect of antistrip additives on the properties of polymer-modified asphalt binders and mixtures. Transportation Research Record 1994; 1436, 108-114.

[14] Lu X, Isacsson U. Rheological characterization of styrene-butadiene-styrenecopolymer modified bitumens. Construction and Building Materials 1997; 11, 23-32.

[15] Kök BV, Yılmaz M, Guler M. Evaluation of high temperature performance of SBS+ Gilsonite modified binder. Fuel 2011; 90, 3093-3099.

[16] Yilmaz M, Çeloglu ME. Effects of SBS and different natural asphalts on the properties of bituminous binders and mixtures. Construction and Building Materials 2013; 44, 533-540.

[17] Kök BV, Y1lmaz M, Akpolat M. Effect of CR and FT-paraffin versus SBS modification in terms of conventional and rheological properties. International Journal of Pavement Engineering 2016; 18(12), 1052-1059.

[18] Zaniewski JP, Pumphrey ME. Evaluation of performance graded asphalt binder equipment and testing protocol. Asphalt Technology Program 2004; 107.

[19] Zooro, SE, Suparma LB. Laboratory Design and Investigation of the Properties of Continuously Graded Asphaltic Concrete Containing Recycled Plastics Aggregate Replacement (Plastiphalt). Cementand Concrete Composite 2000; ISSN 0958-9465, England, 22: 233-242 .

[20] Kaloush, KE, Witczak MW. J. Assoc. Asphalt Paving Technol 2002; 71, 278.

[21] Little DN, Button JW, Youssef H. Transportation Research Board 1993; 1417, 49.

[22] Feeley A.J. UTM-5P, Universal testing machine hardware reference manual, Industrial Process Controls Limited,,BoroniaAustralia 1994. 